\title{
ALIENAÇÃO PARENTAL: O RIGOR FORMAL E AS RESPOSTAS DO JUDICIÁRIO ÀS DEMANDAS DA SOCIEDADE
}

Leonora Roizen Albek Oliven*

\begin{abstract}
RESUMO:
A Alienação Parental é um fenômeno em que os genitores, ou um terceiro cuidador, buscam denegrir um ao outro utilizando, em geral, os filhos como objeto da sua vingança. Afastandose da parentalidade, confundem os afetos conjugais e se servem dos filhos, que podem se tornar objeto do litígio conjugal. Ao fazer pedidos em nome do outro, a criança poderá introjetar o discurso de abandono do alienante. O estudo interdisciplinar de como o Poder Judiciário está aplicando a lei e enfrentando este fenômeno poderá fornecer elementos para a melhor compreensão da família brasileira para a proteção da virulência da Alienação Parental.
\end{abstract}

PALAVRAS CHAVE: famílias; parentalidade; alienação parental; direitos fundamentais; poder judiciário.

\section{PARENTAL ALIENATION: THE FORMAL RIGOR AND THE RESPONSES OF THE JUDICIARY TO THE DEMANDS OF SOCIETY}

\begin{abstract}
:
Parental Alienation is a phenomenon in which the parents, or a third caregiver, seek to denigrate one another by generally using children as the object of their revenge. Moving away from parenting, they confuse conjugal affections and use children, which can become the object of conjugal litigation. When making requests on behalf of the other, the child may introject the alienator's abandonment speech. The interdisciplinary study of how the judiciary is applying the law and facing this phenomenon may provide elements for a better understanding of the Brazilian family to protect the virulence of Parental Alienation.
\end{abstract}

\section{KEYWORDS:}

families; parenting; parental alienation fundamental rights; judiciary.

\section{INTRODUÇÃO}

O Brasil é vanguarda no enfrentamento ao fenômeno da alienação parental. Em 26 de agosto de 2010 foi publicada a Lei n 12.318 que dispõe sobre formas para se encarar de frente o tema e proteger da imensa violência. Mas qual é a resposta do judiciário - e da sociedade ao fenômeno? Decorrente de um conflito familiar, geralmente advindo da confusão entre a

\footnotetext{
* Doutora em Direito, PPGD-UVA com a tese "Famílias plurais: leitura histórico-jurídica das reconfigurações familiares no Brasil"; mestre em Psicanálise, Saúde e Sociedade, UVA. Advogada. Coordenadora do Curso de Graduação em Direito, docente na graduação em direito das famílias e das sucessões e colaboradora do PPGDUVA. leonora.oliven@gmail.com telefone (21) 981235297 e endereço para acessar o lattes http://lattes.cnpq.br/1070351326253691
} 
conjugalidade e a parentalidade, que transborda e atinge a relação materno-paterno-filial criando um hiato relacional, ele pode ser avassalador para as famílias.

As reconfigurações familiares podem ter importante papel nesse percurso. A passagem das famílias hierarquizadas em modelo conservador e patriarcal para as famílias igualitárias e plurais teve um ritmo próprio que por vezes é objeto de retrocessos. As mudanças nas mentalidades demandam um processo aparentemente lento e admitir que a historicidade das famílias e dos institutos jurídicos formadores do contexto contemporâneo suportam os costumes sociais e das famílias amplia as possibilidades de análises nas relações parentais em diferentes conjunturas.

Há também um histórico de inscrição social e pessoal e a função de identificação e da ocupação de um espaço no grupo familiar. Determinante na formação do sujeito, ele é relevante, pois é o primeiro lugar de aprendizado e de realização da pessoa e o acompanhará por toda a sua existência.

Há pais que transformam os seus sentimentos de mágoas decorrentes da separação em litígios intermináveis e usam os filhos como objeto da sua vingança. Ou ainda cuidadores que exercem esse papel e que fazem exigências em nome das crianças. Ao crescer sobreinvestidos de funções que terão que desempenhar e preteridos pelo desejo do outro, é provável haver reflexos sociais e jurídicos.

A problemática será construída em perspectiva que permita a abordagem do fenômeno da alienação parental à luz do direito das famílias e de forma interdisciplinar. A utilização de ferramentas da metapsicologia poderá permitir uma leitura sensível e diferenciada das funções parentais e a compreensão dos riscos na desconstrução do poder simbólico dos pais. Amparado na teoria psicanalítica, nas pesquisas bibliográficas, abrangendo doutrina e textos legais, há dois pontos focais: o primeiro de conhecimento e de compreensão do fenômeno; o segundo na investigação de qual é a resposta do poder judiciário sob o prisma da satisfação e da composição dos litígios.

Parte-se então para a verificação de qual seria a função ideal da lei que dispõe sobre a alienação parental: protetiva aos interesses filiais e parentais ou de sanção? Como torná-la eficaz? Busca-se assim a construção de argumentos que permitam refletir sobre a potência da intervenção judicial não apenas como satisfativas da atividade jurisdicional, mas da real função de composição dos conflitos. 
O reconhecimento de que o direito das famílias tem complexidade transdisciplinar advém da premissa de que a família é uma instituição jurídica, mas também social. Dessa forma, acredita-se haver interseção entre o Direito e a Cultura, e na formação do sujeito. A subjetividade é um valor a ser preservado e protegido. Assim, a base teórica que suporta esse estudo poderá promover soluções que também garantam a expansão da personalidade mas também o alargamento do conceito de família.

1. A interlocução com as novas famílias.

As reconstituições familiares contemporâneas admitem a pluralidade relacional. Essa nova plástica apresenta outras dinâmicas e a inserção de novos atores, com o desempenho de diferentes papeis. Os modelos até então estabelecidos como ideais, ou ao menos como majoritários por um determinado grupo, perdem espaço. A família patriarcal construída no modelo colonial híbrido brasileiro toma novos rumos. Rompendo paradigmas que marcavam a mulher como representação da satisfação marital e dos filhos como a resposta aos seus desejos e necessidades de procriação para a transmissão do nome da propriedade, a família mergulha em uma crise da qual sairá totalmente modificada.

O papel da mulher se modifica. Ao se inserir no mercado de trabalho, disputado palmo a palmo, ainda que em desigualdade de condições, faz como que saia do ambiente doméstico, do "centro das rotinas familiares" (MATTA, 1991, p.51) e busque nova identidade. No ambiente antes eminentemente masculino, a rua, há um espaço a ser conquistado que implica em independência e encontro de novas identidades.

O exercício da função materna deixa de ser a única atividade da mulher e impõe ao homem outras responsabilidades com a família. Os filhos saiam do estado de sujeição para ocupar o seu lugar de sujeito de direito. A criança que no Séc. XVII representava a continuidade do ciclo familiar e "pertencia à linhagem tanto quanto aos pais" (GÉLIS, 2009, p.306) passa a demandar cuidados e a ter direitos. Ao intensificar a convivência entre pais e filhos, o novo paradigma filial demanda o exercício da paternidade em compartilhamento de autoridade parental.

A família deixa de ser um organismo exclusivo. O sistema torna-se aberto, no qual as partes convergem para um resultado comum. Consubstanciadas no afeto, a nova família tem 
por interesse a vida em comum e a expansão da personalidade. É possível perceber a variedade na formação de conjugalidades autônomas e parentais simultâneas.

Em diferentes representações, o desgaste do modelo até então estabelecidos evidenciam as mudanças comportamentais e sociais. Considerando que a sociologia identifica a relação entre direito e sociedade, é possível partir da premissa de que cada sociedade tem as suas peculiaridades e que não se faz necessária para a universalidade ou a manutenção das mesmas normas nas mais diversas representações. Se houve mudanças, as normas jurídicas anteriores podem deixar de ter eficácia e devem ser revistas. O direito é uma construção social, indispensável, mas contingente; possível, mas incerto. Para que se possa então avaliar o direito adequado a cada sociedade, é forçoso partir da premissa de que o mesmo direito não tem reconhecimento em todas as sociedades. O respeito às particularidades e a abstração se fazem necessários, pois a sociologia não irá compartilhar das orientações normativas (LUHMANN, 2009).

Ao recolher a experiência social e jurídica daquele grupo, torna-se possível um novo conhecimento jurídico que procure contemplar as suas demandas. Ao seu tempo, avançando e rompendo dogmas; com períodos de latência, também enfrentando as resistências que pretendem a manutenção de um sistema conhecido. Assim, a verificação entre a história social e o direito, aproximando o diálogo entre as fontes se faz imprescindível. Esse método possivelmente permitirá que a análise dos fatos não à luz da experiência, mas a partir das experiências, daquilo que há de mais profundo na identidade daquele grupo social, com uma série de categorias que define e singulariza esse homem em relação aos demais (GROSSI, 2010).

Esses vínculos familiares são criadores de direitos e de deveres, atribuem poderes e estabelecem padrões comportamentais, pois o "sujeito do direito é o homem, destinatário da norma jurídica", do hominum causa omne ius constitutum est ${ }^{1}$ (PEREIRA, 2007, p.41). Esse sujeito ocupa espaço jurídico privilegiado na base das relações jurídicas e a ele "se reserva um posto avançado no sistema jurídico, a partir da noção de pessoa" (FACHIN, 2006, p.31).

As ações pelo reconhecimento das famílias informais têm um ritmo que se acelerou com o movimento divorcista. O papel fundamental na busca de uma resposta jurídica que possibilitasse às pessoas e livre escolha de como configurar a família ensejou a luta pelo

${ }^{1}$ Por causa do homem todo direito se constitui.

CONPEDI LAW REVIEW | Braga - Portugal | v. 3 | n. 2 | p. 503 - 521 | JUL/DEZ. 2017 
divórcio no Brasil. A partir de então, torna-se possível a configuração de outras possibilidades de famílias, como a mosaico ou pluriparentais, decorrentes das reconfigurações múltiplas.

Para as famílias homoafetivas, o percurso foi mais demorado. A conquista aos direitos civis familiares torna-se consistente a partir de 2011 e decorre de lutas em defesa de respeito e igualdade. As limitações na realização da dignidade, da livre escolha e da individualidade parecem ter sido superadas pelo ativismo judicial ${ }^{2}$, mas há resistências no parlamento conservador ${ }^{3}$. Os costumes arraigados nas intolerâncias são objeto de constante enfrentamento ${ }^{4}$, percebido na historicidade dos três principais documentos da legislação brasileira. São discriminatórios ao tratar das diferenças entre homens e mulheres, do casamento como instituto legitimador da família heteronormativa e da filiação legítima. Os diferentes movimentos legislativos revelam o longo percurso e a interferência da própria sociedade para se estruturar como plural ${ }^{5}$.

Se de um lado há embates sociais que possibilitam os avanços e legitimam as novas famílias, há um caminho obscuro que esconde anseios que poderão ser revelados ao longo da experiência familiar. As novas famílias também apontam sentimentos perturbadores. Eles podem advir de mágoas e de ciúmes pelo ingresso de um novo parceiro na família, modificando a dinâmica e tornando-o, por vezes, um intruso na perspectiva do ressentido.

Ao término da conjugalidade ou do relacionamento amoroso, há uma torrente de emoções decorrentes da perda do objeto de desejo. Durante um determinado tempo, ele foi a resposta ou a correspondência a uma alegoria de plenitude amorosa. O ideário de formação de uma vida plena e feliz em uma família que deveria corresponder a um modelo delimitado anteriormente não mais se oferece.

A perda desse objeto de desejo pode implicar em um processo no qual o enlutado conseguirá ou não deslocar o desejo para outro objeto, não necessariamente amoroso. Em outras oportunidades, culmina em um processo de melancolia passível de uma vitimização, como

\footnotetext{
${ }^{2}$ O Supremo Tribunal Federal reconheceu, com repercussão geral em ADPF nº. 132/RJ e ADI no 4.277/DF, as configuração de união estável entre pessoas do mesmo sexo; 2011.

${ }^{3}$ PL 6.583/2013, Estatuto da Família, indica uma única possibilidade de configuração familiar, triangular, formada por um homem, uma mulher e os filhos.

${ }^{4} \mathrm{PLS} \mathrm{n}{ }^{\circ} 470 / 2013$, Estatuto das Famílias, comtempla as famílias plurais, reconhecendo como necessária a proteção à família em qualquer de suas modalidades e de todas as pessoas que a integram.

${ }^{5}$ Em 2011, o Supremo Tribunal Federal, com repercussão geral em ADPF no ${ }^{\circ}$ 132/RJ e ADI no 4.277/DF, reconheceu as famílias homoafetivas como suscetíveis de serem configuradas como união estável. A Resolução ${ }^{\circ}$ 175/2013, CNJ, dispõe sobre a habilitação, celebração de casamento civil, ou de conversão de união estável em casamento, entre pessoas de mesmo sexo.
} 
observado por Freud (1917) em Luto e Melancolia. O luto é um processo lento, porém inerente na perda de um ente querido. O reconhecimento da perda concluirá o luto e possibilitará o investimento em novos interesses, mas o apego exacerbado, a negativa em reconhecer a perda, poderá se cristalizar no objeto de desejo.

Nessa disputa, é possível que o casal renove nesse conflito outros preexistentes à separação e podem renovar indefinidamente os sintomas que levaram ao enfraquecimento da relação amorosa. Para ter certeza de suas convicções, creem na importância da exposição pública do suplício e da vida pessoal. Para legitimar o seu sofrimento, imputam ao outro a responsabilidade pelo desfazimento da conjugalidade e pelo fracasso da relação.

O problema está no outro. A assertiva parece fortalecer a vitimização e trazer na esteira incriminações recíprocas que podem atingir os filhos. Aqueles que estabeleceriam e eternizariam os laços de afeto tornam-se joguetes para satisfazer a vendeta decorrente da ferida narcísica. Os filhos tornam-se os espelhos do insucesso e suportam as incoerências do par de opostos amor-ódio.

A não elaboração do luto pela perda da separação é capaz de gerar uma angústia de castigar o outro para satisfazer a sua perda. Não tendo acesso à conjugalidade, a atuação em face do ex-par se dará através da relação parental buscando aniquilar a representação do outro progenitor. Esse processo pode ser desempenhado de várias formas e frustra a relação maternopaterno-filial. É um procedimento devastador para pais e filhos. Essa família disfuncional é capaz de excluir um dos genitores da vida da criança, depreciando não apenas o outro, mas a relação até então existente ou qualquer outra possibilidade de construção, até mesmo matando o outro em vida.

\section{O fenômeno Alienação Parental.}

Nos casos de divórcios eternizados pelo manuseio de artifícios que parecem querem prender o ex-casal, é possível identificar a exacerbação dos litígios conjugais sob a forma de ações judiciais que tem como questão de fundo o direito material. Em outras, apenas o desejo. Discussões intermináveis sobre os alimentos, a partilha de bens e até mesmo a oposição ao 
divórcio, o que sequer é cabível, considerando tratar-se de um direito potestativo independente e autônomo de causa ou de lapso temporal ${ }^{6}$, acabam por criar uma teia para capturar o outro.

Por vezes, é possível constatar que os filhos se tornam os objetos dessas demandas do casal. As exigências que são feitas não são exatamente as dos filhos, mas em seu nome sem que eles sequer percebam do que se trata. Podem ser os pais ou um terceiro cuidador que tenha influencia e interferência na socialização e criação da criança, quem faz os pedidos. Não se trata de um pleito da criança, que nem mesmo compreende a extensão do que se passa, mas acaba participando a ponto de entrar em crise de lealdade para com o guardião imediato, aquele com quem tem maior proximidade.

Ao não conseguir discernir a exata extensão da narrativa, já que não possui essa capacidade analítica, acaba internalizando o falso discurso do abandono. Com ele, surgem as dúvidas ao amor do outro, capazes de colocar fim a qualquer possibilidade ao diálogo.

O investimento no par amor-ódio parece explicitar sentimentos como vingança e ciúmes decorrentes de estados de exigências para a satisfação de seus desejos. Essa ação encobre não apenas a questão de fundo, mas atinge a vida psíquica dos filhos.

A experiência de alienar o pai ou a mãe constitui a Alienação Parental (AP). Trata-se de um fenômeno de desqualificação, de alijamento e até mesmo de implantação de falsa memórias na vida dos filhos com a finalidade específica de eliminar as relações de afeto entre pais e filhos. É intencional e engendrada de forma calculada.

O fenômeno foi especificamente percebido por Richard A. Gardner, nos estados Unidos na década de 1980. O psiquiatra atuava em ações judiciais de custódia de filhos e observou como os pais destituem a autoridade do ex-par e arruínam a relação filial. Um processo de degradação do outro genitor. O desdém em relação aos pais os desvaloriza e tem por objetivo específico reduzir e até mesmo inibir o contato íntimo e estreito entre pais e filhos. Edificar uma biografia que deprecia um ou ambos os pais, pois possível a atuação e um terceiro nesse processo, pode tornar estéril as relações familiares e os seus afetos.

A síndrome se fortalece quando no "transtorno no qual um genitor aliena a criança contra o outro genitor" (GARDNER, 2002) o filho se torna um aliado e contribui com a própria alienação. Para o pesquisador, trata-se de abuso emocional que fragiliza o relacionamento entre pais e filhos e traduz a disfunção parental. Na observação, acredita que devam ser observados

${ }^{6}$ Emenda Constitucional $\mathrm{n}^{\mathrm{o}}$ 66/2010.

CONPEDI LAW REVIEW | Braga - Portugal | v. 3 | n. 2 | p. 503 - 521 | JUL/DEZ. 2017 
especificamente oito sintomas $^{7}$ na criança para a caracterização como síndrome. E, caso ela apresente a maioria dos mesmos, deve-se caracterizar o evento como uma síndrome, havendo pontos de contato que a fundamentam.

A Síndrome da Alienação Parental - SAP - pode ser evidenciada pela "combinação das instruções de um genitor e contribuições da própria criança para caluniar o genitor-alvo" (GARDNER, 2002). Nos casos de efetivo abuso parental e a intolerância dos filhos aos pais, o conceito de alienação parental não se aplica, sendo o abandono e os maus-tratos justificativas hábeis a justificar a hostilidade dos filhos.

O sujeito se constitui também através das identificações que estabelece com os seus pais e o espaço em que ocupa na família exige o convívio parental. A exclusão realizada em processo de destruição do outro genitor poderá desencadear sentimentos de angústia e medo em face do alienado. Não do alienante: ainda que a sua fala seja desagradável, o filho tende a ter sentimentos de lealdade, como se enxergasse uma fragilidade a ser protegida. Possivelmente por ser o alienante a pessoa que desempenha os cuidados cotidianos, com acesso aos sentimentos. Esse cuidado filial desencadeia uma conduta agressiva com o alienado.

Esse é o jogo: usar o filho como condutor da vingança e destruir o seu adversário. A modificação na percepção das relações parentais fica escondida sob um véu de verdades criadas pelo alienante e tem força para privar pais e filhos do convívio familiar. Não percebem os seus filhos como sujeitos, mas como coisa a ser usada na satisfação de seu gozo, retomando um processo de coisificação da criança.

A confusão entre os conceitos de parentalidade e de conjugalidade estabelecidas pelo alienante e a entrada do alienado nesse processo, ainda que contra a sua vontade, desestabiliza o filho. As exigências que são feitas em seu nome não correspondem às suas expectativas e os expõem a conflitos alheios. Nesse percurso "o filho é utilizado como instrumento da agressividade, sendo induzido a odiar o outro genitor. Trata-se de uma verdadeira campanha de desmoralização" (DIAS, 2015, p. 546). As crianças acabam por internalizar as falas parentais,

\footnotetext{
${ }^{7}$ Gardner (2002) propõe a investigação de oito sintomas para a caracterização da SAP: a campanha denegritória contra o genitor alienado; racionalizações fracas, absurdas ou frívolas para a depreciação; falta de ambivalência; o fenômeno do "pensador independente"; apoio automático ao genitor alienador no conflito parental; ausência de culpa sobre a crueldade a e/ou a exploração contra o genitor alienado; a presença de encenações 'encomendadas'; propagação da animosidade aos amigos e/ou à família extensa do genitor alienado.
} 
se solidarizando através das identificações com um discurso pertence a uma outra pessoa (FAIMBERG, 2001, p.129-145).

A campanha de desqualificação do outro atinge a criança também em outro aspecto: a sua desqualificação pessoal. Ao considerar a identificação como a expressão mais primária de uma ligação afetiva com outra pessoa (FREUD, 1921) e o seu papel básico no Complexo de Édipo, o processo de diabolização dos pais interfere na autoestima dos filhos, que se reconhecem naqueles. Ao educar uma criança para se desprender de seus pais, pode haver um desprendimento de si mesmo.

A abordagem desse fenômeno pelo Poder Judiciário depende da escuta da narrativa infantil e da percepção sobre a sua veracidade não apenas no mundo interno. O estudo da alienação parental "traz para o campo da objetividade os fenômenos das relações familiares" (GROENINGA, 2008, p.119), escancarando oportunidades de diálogos e reflexões. Para além do simbólico (des)construído pela alienação, busca-se verificar se o enunciado é do filho e se está ou não contaminado pelo desejo do alienante. As dificuldades em diagnósticos conclusivos sobre a alienação parental justificam os cuidados e a atividade multidisciplinar na investigação do fenômeno para tornar possível a compreensão e atuação em casos de famílias em litígio.

\section{A Lei da Alienação Parental.}

A compreensão da importância na manutenção das relações materno-paterno-filiais conduz a estruturação de medidas que coíbam a prática do fenômeno da AP. A criação de instrumentos que possam garantir as melhores condições psíquicas e emocionais aos filhos de pais não conviventes reconhece como relevante a integração para as famílias constituídas de forma diversa às nucleares.

O Projeto de Lei n 4.053, de 2008, de iniciativa do Deputado Régis de Oliveira, com o objetivo de "definir o que é alienação parental, mediante a fixação e parâmetros para a sua caracterização, a par de estabelecer medidas a inibir essa prática ${ }^{8 "}$ (BRASIL, 2008) deu origem à Lei ${ }^{\circ}$ 12.318/2010, sancionada em 26 de agosto de 2010. A norma apresenta um conceito não absoluto de alienação parental e exemplifica atos que possam ser caracterizados como de alienação parental. Sensível às demandas familiares, protege as relações entre pais e filhos,

\footnotetext{
${ }_{8}^{8}$ Disponível em http://www.camara.gov.br/sileg/integras/601514.pdf Acesso em 31 mai. 2017 CONPEDI LAW REVIEW | Braga - Portugal | v. 3 | n. 2 | p. 503 - 521 | JUL/DEZ. 2017
} 
mas também à relação avoenga. A alienação fere direito fundamental da criança e impõe medidas protetivas assecuratórias do bem-estar de toda a família.

A previsão de equipe multidisciplinar demonstra a percepção de que a história revelada nos autos pode estar impregnada de sentimentos do alienante. A perícia prevista deve assegurar a escuta diferenciada de pais e filhos para evitar a calcificação da fala alheia e não reforçar a história do alienante. A pretensão em aproximar pais e filhos e reduzir os efeitos do distanciamento se dá em favor da convivência saudável, estabelecendo ou consolidando o vínculo da criança com os pais.

As medidas punitivas são controvertidas e demandam indagações sobre a aplicação eficaz. Podem ser aplicadas individualmente ou de forma conjuntiva, dependendo da situação e da análise do julgador. No caso da advertência, é possível que o alienante que esteja tão somente confuso com o fim da relação compreenda qual prejudicial a prática. Trata-se de um processo de conscientização e de esclarecimento ao alienante, e se eficaz facilitará o diálogo.

A ampliação do regime de convivência pode ser importante, especialmente nos casos em que o alienante se usa de falsas falas ou memórias para agenciar o distanciamento entre o filho e o outro genitor. Esse aumento do direito convivencial poderá possibilitar o restabelecimento do vínculo e a completude das identificações.

No que se refere e a multa, acredita-se que a sua eficácia seja controvertida. Além da lei não informar em favor de quem será convertido o pagamento, há pessoas que se estabelecem em torno da possibilidade de pagar pelas suas atitudes, renovando-as. A reversão da multa em favor da criança parece ser a medida mais adequada, pois ela é grande vítima do fenômeno, podendo o genitor demandar, se o caso, através da responsabilidade civil autônoma.

A obrigatoriedade em realizar tratamento psicológico do alienante é feita de forma individual. Não se trata de uma terapia de família, mas focado no comportamento do genitor conturbado pela separação, para que compreenda a extensão do que está destruindo. $\mathrm{O}$ esclarecimento é individual e não há como delimitar tempo mínimo ou máximo para a compreensão do fenômeno. Ou da elaboração do luto.

A inversão da guarda é uma das formas como se busca a recomposição das relações afetadas pela SAP. Talvez a sua eficácia se fizesse mais presente quando da publicação da norma em 2010, momento em que a guarda seria compartilhada sempre que possível. Ainda havia significativa fixação de guarda unilateral, como se o filho fosse coisa pertencente a um 
dos pais. A partir de $2014^{9}$ a guarda compartilhada tornou-se a guarda preferencial a ser atribuída entre casais não conviventes, sempre respeitado o melhor interesse da criança.

O legítimo exercício do poder familiar - da autoridade parental - garantem o estreito direito convivencial. Os genitores poderão exercitar a parentalidade e a responsabilidade inerente à função através da participação conjunta na vida do filho. Garantir que as figuras materna e paterna sejam Através da guarda compartilhada, permite-se que ambos os pais exercitem de forma plena a autoridade e a responsabilidade parental. Os deveres inerentes ao poder familiar, para que sejam experenciados em sua plenitude, demandam a participação conjunta do par parental na vida dos filhos, desde que não haja riscos para as crianças. As figuras materna e paterna não devem ser meras lembranças ou imagens, mas determinantes no crescimento e no desenvolvimento infanto-juvenil.

Sob este prisma, foi proposta uma forma de exercício da guarda onde ambos os pais possam permanecer na companhia - e na vida - dos filhos, evitando-se que o fim da conjugalidade imprima uma marca de abandono na criança. $\mathrm{O}$ incentivo à manutenção da convivência fortalece os laços afetivos familiares, sendo "modo a assegurar aos filhos a convivência e o acesso livres a ambos. Nesta modalidade, a guarda é substituída pelo direito à convivência dos filhos em relação aos pais" (LÔBO, 2009, p.178). A responsabilização dela decorrente é inerente à autoridade parental. A guarda não indica divisões nas relações entre pais e filhos e não há qualquer pretensão em alternância nas responsabilidades, mas de exercício conjunto. O conforto afetivo aos filhos decorre também da colaboração mútua dos pais sempre no interesse dos filhos.

A delimitação de um domicílio ao filho sempre deverá existir, mas o outro pai deve estar ciente de onde o seu filho reside. Não está ao livre arbítrio de nenhum dos pais levar a criança sem informar ao outro. No que se refere aos filhos, precisam reconhecer o seu espaço e os contornos estabelecidos como regras dentro da casa materna e/ou paterna, se o caso.

Já a suspensão da autoridade parental, medida extrema e dolorosa, é dependente do comprometimento desses genitores para com a alienação. De quem ele é aliado? De seu desejo ou de seu filho? A alienação é prática abusiva aos direitos filiais e perniciosa o suficiente a ensejar a suspensão do poder familiar.

${ }^{9}$ Lei $^{\circ}{ }^{13} .058 / 2014$.

CONPEDI LAW REVIEW | Braga - Portugal | v. 3 | n. 2 | p. 503 - 521 | JUL/DEZ. 2017 
Há situações em que também são propostas demandas suscitando alienação parental que podem ser encaradas como alienação inversa. Nesse caso, percebendo-se que a questão e fundo do autor é causar discórdia na relação familiar ou um enriquecimento sem causa, propõe-se que seja caracterizado como alienação parental e responda pela mesma norma.

Essa compreensão deveria permitir o exercício autônomo da conjugalidade, da mesma forma que da parentalidade, observando a Proteção Integral da Criança e do Adolescente, direito constitucionalmente garantido para a realização biopsíquica do sujeito. A abrangência não se dá apenas no âmbito da família nuclear, mas de todo o grupo familiar e também no Poder Judiciário, a ser tocado pela necessidade de preservar também a vitalidade psíquica da criança. A lei que enfrenta a AP busca fornecer instrumentos que impeçam a instituição do fenômeno, ou que já estejam estabelecidos e precisem de intervenção.

\section{Algumas respostas do Poder Judiciário.}

Na busca de instrumentos de proteção às famílias, se faz necessário conhecer a resposta do Poder Judiciário ao proposto pela lei da alienação parental. Esse enfrentamento possibilitará analisar a efetividade da norma e a construção e argumentos que possibilitem a utilização de recursos restauradores dos diálogos familiares.

Não se procura uma resposta quantitativa - e o Judiciário tampouco revela os seus números. A dificuldade em obter dados estatísticos em sistemas ou através de pesquisa de campo possivelmente advém não apenas do segredo de justiça ao qual se submetem tais ações, mas também de resistências para enfrentar de frente a sua existência e a busca pela resposta adequada à recomposição relacional. A autocomposição oportunizada por uma justiça coexistencial, fonte de reparo "de relacionamentos prolongados, em vez de simplesmente julgar as partes vencedoras ou vencidas" (CAPPELLETTI \& GARTH, 1988, p.87), talvez reduza a expectativa da solução externa.

A criminalização de atos que promovam a alienação parental está em debate. O projeto de lei em trâmite na Câmara dos Deputados pretende tipificar a prática "com o intuito de proibir, dificultar ou modificar a convivência com ascendente, descendente ou colaterais, bem como àqueles que a vítima mantenha vínculos de parentalidade de qualquer natureza ${ }^{10}$ " sob a

${ }^{10} \mathrm{PLC} \mathrm{n}^{\circ}$ 448/2016. Disponível em http://www.camara.gov.br Acesso em 01 jun. 2017.

CONPEDI LAW REVIEW | Braga - Portugal | v. 3 | n. 2 | p. 503 - 521 | JUL/DEZ. 2017 
justificativa de "crucial relevância em homenagem ao princípio da proteção integral, imputando a quem comete qualquer ato que vise destruir laços de afetividade, sanção criminal". No PLC, a vítima é a criança, fortalecendo a ideia de que se trata de um direito fundamental garantir a ampla convivência familiar. Ainda se discute o caráter pedagógico-sanção da prisão do alienante, tratado no projeto como temor reverencial para inibir os atos.

Há pontos de contato entre o PLC e a legislação argentina, que desde 1993 tipifica como crime $^{11}$ atos que possam obstruir o acesso dos pais aos filhos, com aumento de pena se a criança for menor de dez anos. No México, em 2014 foi alterado o Código Civil ${ }^{12}$ para reconhecer a prática da alienação parental como uma violência familiar. A expressão reconhece a extensão do fenômeno, que atinge não apenas os filhos, mas todas as pessoas que compõem a estrutura familiar pelos vínculos de afeto.

Para delinear a aplicação da norma no Brasil, serão apresentadas três decisões recentes e analisadas as sanções aplicadas ao alienante. Em segredo de justiça, a análise se dá apenas através das ementas publicadas.

Em ação de guarda, o juízo da $3^{\text {a }}$ Vara de Família e das Sucessões do Tribunal de São Paulo $^{13}$ julgou procedente o pedido paterno formulado em ação de guarda para deferir a guarda unilateral e suspender as visitas maternas por verificada a prática de alienação parental.

A drástica decisão permite supor encontros e entrevistas com profissionais de confiança do Juízo. É possível conjecturar que a avaliação técnica psicológica concluindo pela consolidação da alienação, material no qual se apoiam tais decisões, indicava que a mãe alimentava animosidades na relação paterno-filial e que o convívio materno seria pernicioso ao filho. Trata-se de uma decisão na qual a opção pela inversão de guarda é acompanhada da exclusão das visitas maternas. Aplica-se uma sanção à mãe que possivelmente atinge o filho em via reflexa ao proibir o convívio. A privação da comunicação entre mães, pais e filhos é medida extrema em qualquer tipo de litígio e a aplicação da severa pena, impedindo o contato, depende de provas inequívocas da projeção da síndrome. Em regra, a interrupção do convívio

\footnotetext{
${ }^{11}$ Lei n 24.270 de 3 de noviembre de 1993. Disponível em http://www.afamse.org.ar/files/Ley_24270.pdf Acesso em 01 jun. 2017.

${ }^{12}$ Alteração de 9 de maio de 2014: Artículo 323 Septimus.- Comete violencia familiar el integrante de la familia que transforma la conciencia de un menor con el objeto de impedir, obstaculizar o destruir sus vínculos con uno de sus progenitores. Disponível em http://www.ordenjuridico.gob.mx Acesso em 01 jun. 2014.

${ }^{13}$ Fóruns Regionais e Distritais II - Santo Amaro e Ibirapuera Cível $3^{\text {a }}$ Vara da Família e Sucessões, autos $n^{\circ}$ 1042945-23.2016.8.26.0002. Disponível em https://esaj.tjsp.jus.br e http://www.sandravilela.adv.br Acesso em 31 mai. 2017.
} 
não restaura o diálogo, mas fomenta a disputa parental, desgastando cada vez mais a relação familiar.

O dever de cautela se impõe a todos os envolvidos em demandas familiares. Deve-se preferencialmente buscar a compreensão da situação problema, compreendendo que reatar os laços é a opção a ser considerada. O resgate relacional entre pais e filhos é a proposta para evitar que a alienação parental se instaure como um fenômeno psíquico devastador.

Em decisão proferida pela Décima Oitava Câmara Cível, TJRJ, em 22 de fevereiro de 2017, sendo Relator Des (a). Carlos Eduardo da Rosa da Fonseca Passos ${ }^{14}$, foi decidido em Agravo de Instrumento em ação de guarda de crianças com sete e catorze anos de idade em que foi verificada haver indícios de alienação parental praticada pelo genitor e decidiu o juiz a quo pela "suspensão integral da visitação paterna e do contato absoluto dos menores com o pai por três meses". O Tribunal entendeu que a medida era drástica, excessiva e que a privação do convívio, no caso, era injustificada. Para evitar que a alienação se perpetuasse, ficou estipulada a visita assistida como forma de coibir a manutenção da prática da alienação sem perda do contato entre pai e filhos. Também foi determinado o acompanhamento psicológico.

A imposição de visitas assistidas é medida que agrega. Não impede o convívio familiar, podendo criar condições adequadas para que não se insista na cristalização da alienação. A medida contempla a preservação as relações familiares e no caso sob comento houve a determinação de realização de acompanhamento psicológico. Questiona-se, no caso, como será feito esse acompanhamento. Incumbe ao Poder Público oferecer as condições adequadas e necessárias ás terapias ou é possível impor às partes que suportem esse custo? Ainda que não se trate de gratuidade dos serviços judiciários, os acompanhamentos psicológicos são reconhecidamente custosos e podem impactar na economia doméstica. O descumprimento da determinação poderá ensejar outra sanção ou a execução da determinação? Conhecer a elaboração e o acompanhamento do plano de trabalho nos casos em que há encaminhamento para o acompanhamento especializado poderá impactar de forma positiva na restruturação familiar.

Em decisão proferida pelo TJRS em 09 de março de 2017 pela Oitava Câmara Cível ${ }^{15}$, Relator Des. Luiz Felipe Brasil Santos foi mantida a reversão de guarda de filho que estava com

\footnotetext{
${ }^{14}$ Autos no 0065657-25.2016.8.19.0000 Disponível em http://www4.tjrj.jus.br Acesso em 31 mai. 2017.

${ }^{15}$ Embargos de Declaração No 70071276497 Disponível em http://www.tjrs.jus.br Acesso em 31 mai. 2017.
} CONPEDI LAW REVIEW | Braga - Portugal | v. 3 | n. 2 | p. 503 - 521 | JUL/DEZ. 2017 
o pai para permanecer em guarda unilateral com a mãe. A decisão considera haver nos autos evidências da prática paterna de alienação parental em face da mãe.

No caso em análise, acredita-se que os laudos periciais tenham assinalado atos que caracterizam a conduta alienante paterna. As avaliações técnicas judiciais são conduzidas por profissionais que buscam conhecer a não apenas o sintoma alienação parental, mas a história daquela família. Reduzir o litígio através desse trabalho especializado poderá implicar em restabelecer as relações materno-paterno-filiais, pois o laudo possibilita sugestões e intervenções qualificadas.

A inversão a guarda, determinada como medida protetiva da criança, e não como punitiva ao pai alienante. Se de um lado a sanção pode ser eficaz, nota-se que foi atribuída a guarda unilateral. Considerando que a guarda preferencial é a compartilhada, é possível inferir que o compartilhamento da autoridade parental pode colocar em risco o desenvolvimento da criança. A guarda uniparental, considerada como a exercida tão somente por um dos pais, no caso sob análise pela mãe alienada em decorrência de decisão judicial, a quem competirá, de forma exclusiva, a função e guardiã da criança. Essa determinação não implica no afastamento do genitor não guardião, que possivelmente terá o direito convivencial, e que tampouco teve suspenso o poder familiar. Logo, esse pai alienante, ainda que sem ter a guarda compartilhada, é corresponsável pelo sustento, educação e cuidados com o filho.

As decisões judiciais devem atender ao interesse dos filhos. Eles são titulares do direito fundamental à convivência familiar. A promoção de um ambiente saudável, sustentado no respeito e afeto, são as diretrizes familiares. Ao respeitar a construção da subjetividade da a criança, deve-se criar instrumentos que possibilitem o acesso à convivência familiar, permitindo o desenvolvimento saudável. Acredita-se que dessa forma seja possível evitar, ou ao menos reduzir, a consolidação do fenômeno relacional Alienação Parental.

\section{CONSIDERAÇÕES FINAIS}

As novas famílias permitem os rearranjos nas relações afetivas, mas também inserem novos personagens na dinâmica familiar. A família patriarcal angular perde espaço para a família mosaico, plural, conectada pelo afeto. A relevância na transformação das famílias implica em adequação normativa aos novos modelos. Se a família tem muitas representações, 
a decodificação de determinadas mensagens nas quais o enunciado pode escapar poderá interferir na ressignificação dos papeis em diferentes espaços pessoais e sociais.

A inaptidão para a convivência com as diversidades daí advindas podem criar altercações na nova família. O desejo em manter os antigos laços conjugais transformado em poder através do exercício de ações judiciais ou não, reatualizando os conflitos, pode atingir de forma inexorável os filhos.

Ao conhecer a teoria sobre a alienação parental, a sua configuração e a repercussão na construção do sujeito, se faz necessária a investigação em perspectiva interdisciplinar. Para efetivar a proposta inicial, a abordagem através de instrumentos metapsicológicos se impôs para dar suporte ao conhecimento e extensão do fenômeno da alienação parental.

A constatação que o alienante faz exigências em nome da criança e que ambos acreditam na veracidade do discurso poderá estabelecer um modelo familiar não cooperativo. Reconstruir um caminho saudável demanda reflexões e aprendizados sobre os fenômenos psíquicos para que se possa estabelecer uma relação dialógica, especialmente nas situações de conflitos familiares. A instauração do fenômeno e a sua potencialização, com a transformação em uma patologia caracterizando a síndrome, deve ser enfrentada pelo Direito. Além da função pacificadora social, o ordenamento jurídico trabalha com o princípio de proteção das crianças, por serem pessoas em desenvolvimento e dependentes de garantias específicas, e também das famílias, instituição acolhedora dos afetos.

O estudo cada vez mais se justifica. Seja pela necessidade de se investigar as formas como se estabelece, mas também como tem sido a representação do fenômeno para as famílias e para a sociedade. Nesse caso, ela é revelada pela vontade do Estado não apenas pela descrição de atos que a evidenciam, mas na satisfação manifestada através da judicialização da família. Como se a serviço do litígio e das angústias, o fenômeno busca no discurso jurídico a validação da dor em disputa interminável.

Ao desaguar no Poder Judiciário transformado em violência familiar, atingindo todo o organismo social e em especial os filhos, que acabam por se distanciar física e afetivamente de seus pais alienados, a prática exige uma resposta. Não se trata da consolidação de certezas, mas de uma efetiva da proteção das relações familiares com a tomada de decisões suficientes a reduzir o hiato relacional e que busque restabelecer o diálogo. Considerar o entorno familiar e a compreensão daquela família em específico, tornando as análises atentas ao resultado consistente, é função dos envolvidos com o tema. Para que as decisões não sejam ao final vazias CONPEDI LAW REVIEW | Braga - Portugal | v. 3 | n. 2 | p. 503 - 521 | JUL/DEZ. 2017 
de resultados e cheias de sanções, cada família é ouvida de forma particularizada e considerada individualmente. A busca pela recomposição não se dá em razão da conjugalidade, mas das relações filiais.

As interferências que o Poder Judiciário realiza na família podem romper em definitivo os laços ou efetivar a sua manutenção. A intervenção ativa da equipe multidisciplinar para compreender a extensão do fenômeno e a necessidade de uma intervenção dialógica, sugerida através da mediação familiar de forma simultânea ao acompanhamento psicológico, poderá atenuar o conflito. O conteúdo afetivo decorrente da desordem conjugal é desgastante para os envolvidos e a colaboração para o exercício da co-parentalidade depende de atitudes restaurativas do diálogo.

Acredita-se que as medidas concomitantes possam ter força suficiente para sensibilizar os envolvidos a identificarem a extensão do conflito. A simples punição pode ser uma resposta satisfatória ao alienado ou, se não restar provada a alienação, consolidará a posição do alienante. Em ambas as possibilidades a criança perderá em contato e diálogo familiar. Nesse caso, não há vencedores.

Reorganizar a atividade colaborativa e o canal de comunicação possivelmente possibilitará a conversa para encontrar as melhores respostas aos conflitos, com os pais decidindo ativamente. A responsabilização conjunta pelo resultado permitirá a construção de um novo caminho com diferentes dimensões para as relações parentais.

\section{REFERÊNCIAS BIBLIOGRÁFICAS}

CAPPElletti, M.; GARTH, B. Acesso à Justiça. Porto Alegre: Sergio Antonio Fabris Editor, 1988.

DIAS, M. Manual de Direito das famílias. Porto Alegre: Livraria do Advogado, 2015. FACHIN, L. O Estatuto Jurídico do Patrimônio Mínimo. Rio de Janeiro: Renovar, 2006.

FAIMBERG, H. Escuta da telescopagem das gerações: pertinência psicanalítica do conceito. In: KAES, R. Transmissão da Vida Psíquica Entre Gerações. São Paulo: Casa do Psicólogo, 2001.

FARIAS, Cristiano Chaves de.e ROSENVALD, Nelson. Curso de Direito Civil. Volume 6. Famílias.7 $7^{a}$ edição. São Paulo: Editora Atlas, 2016. 
FREUD, S. (1893-1895). (1913 [1912-13]). Totem e tabu. In: Edição Standard Brasileira das Obras Psicológicas Completas de Sigmund Freud (ESB). Rio de Janeiro: Editora Imago, 1974, v. 13.

. (1917) Luto e Melancolia. In: ESB, op. cit., v. 14.

. (1921) Psicologia de grupo e análise do ego. In: ESB, op. cit., v. 18.

Gagliano, P. S. e PAMPlONA FILHO, R. Novo Curso de Direito Civil. Direito das

famílias. A família em perspectiva constitucional. 2 ed. revista, atualizada e ampliada. São Paulo: Saraiva, 2016.

GARDNER, R. Differentiating between parental alienation syndrome and bona fide abuse-neglect. American Journal of Family Therapy [serial online]. April 1999; 27(2):97. Disponível em: <http://5398011730661013200-a-1802744773732722657-ssites.googlegroups.com/site/alienacaoparental/textos-sobre-sap/Gardner\%281997\%29DIFFERENTIATINGBETWEENPARENTALALIENATIONSYNDROMEANDBON AFIDEABUSE-

NEGLECT.pdf?attachauth=ANoY7crG_mITLhHNMMhTt8A7WzoHGXakWMbVH gCbYc75TDclPCySgcArDbgTW1QjB-

aBrYUd9CYdvHEIKPOG4z2XwORcz11N1LLbikMZ0BAlgZw-

WqmJOBKbwHAV3eG5967TYsXzeD7pjypx7crybD_0FnMRKmmgPC713h0xWXw EnXFW9rVkFNuTt9pPAkOptzk2kDvMf8IkDYiEN-

IQukw0fvX4HmsqYtltFKMIV_9cov5zY90mGFclY99Vn5uTlG46XTzhkaFqgc7dVf Gust7uqd3UKqsOBZDvoQE9CUidk227TDlvtmCVicoE1E1nRQFRrjuWSenMAZYQ vZCzm48ZU_h3Rz4cQA\%3D\%3D\&attredirects=0> Acesso em 01 jun. 2017.

. O DSM-IV tem equivalente para o diagnóstico de Síndrome de Alienação Parental (SAP)? Manuscrito não publicado. Tradução para o português por Rita Rafaeli, 2002. Disponível em <http://www.scribd.com/doc/6155591/Sindrome-daAlienacao-Parental-Richard-Gardner>. Acesso em 01 jun. 2017.

GÉLIS, J. A individuação da criança. In: ARIÈS, P. e DUBY, G. História da Vida Privada. São Paulo: Editora Schwarcz Ltda., 2009.

GROSSI, P. O direito entre poder e ordenamento. Trad. de Arno Dal Ri Junior. Belo Horizonte: Del Rey, 2010.

LÔBO, P. Direito-dever à convivência familiar. Direito das Famílias / Maria Berenice Dias Organizadora, São Paulo: Editora Revista dos Tribunais, 2009. 
LUHMANN, Niklas. Sociologia do Direito I. Rio de Janeiro: Tempo Brasileiro, 1983.

MATTA, R. A Casa \& A Rua - Espaço: casa, rua e outro mundo: o caso do Brasil. Rio de Janeiro: Guanabara Koogan, 1991.

PEREIRA, C. M. S. Instituições de direito civil. Vol. I. Rio de Janeiro: Forense, 2007.

PEREIRA, T. S. O princípio do "melhor interesse da criança" no âmbito das relações familiares. In: GROENINGA, G. e PEREIRA, R. (Coord.) Direito de Família e Psicanálise Rumo a uma nova epistemologia. Rio de Janeiro: Imago, 2003.

\section{LEGISLAÇÃO}

ARGENTINA. Lei n $^{\circ} 24.270$ de 3 de noviembre de 1993

BRASIL. Constituição (1988) Constituição Federal da República Federativa do Brasil. De 05 de outubro de 1988. Brasília, DF: Senado, 1988. . Lei $n^{\circ} 3.071$, de $1^{\circ}$ de janeiro de 1916. Código Civil. Lei $\mathrm{n}^{\circ}$ 10.406, de 11 de janeiro de 2002. Institui o Código Civil. Diário Oficial da União, Brasília, DF, v. 134, n. 248, 11 jan. 2002. Seção 1, p. 1.

. Projeto de Lei $\mathrm{n}^{\circ} 4.053 / 2008$ . Lei $\mathrm{n}^{\mathrm{o}} 12.318 / 2010$, de 26 de agosto de 2010 . Projeto de Lei do Senado no 612/2011. . Resolução no 175, de 14 de maio de 2013, do Conselho Nacional de Justiça. . Projeto de Lei da Câmara n ${ }^{\circ}$ 6.583/2013. Estatuto da Família. . Projeto de Lei do Senado n 470/2013. Estatuto das Famílias. Projeto de Lei da Câmara ${ }^{\circ} 4.448 / 2016$. Acrescenta parágrafos e incisos ao art $3 .^{\circ}$ da

Lei 12.318/2010 que dispõe sobre a alienação parental.

\section{SITES}

http://www.camara.gov.br/sileg/

http://www.ordenjuridico.gob.mx/Documentos/Estatal/Distrito\%20Federal/wo95006.pdf http://www.sandravilela.adv.br http://www4.tjrj.jus.br http://www.tjrs.jus.br http://www.tjsp.jus.br 